\title{
Differential Effects of Drinking Water Quality on Phagocyte Responses of Broiler Chickens Against Fungal and Bacterial Challenges
}

OPEN ACCESS

Edited by:

Xinjiang Lu,

Ningbo University, China

Reviewed by:

Antonio J. Piantino Ferreira,

University of São Paulo, Brazil

Adenilda Cristina Honorio-França,

Universidade Federal de Mato

Grosso, Brazil

*Correspondence:

Daniel R. Barreda

d.barreda@ualberta.ca

Specialty section:

This article was submitted to

Comparative Immunology,

a section of the journal

Frontiers in Immunology

Received: 07 December 2019 Accepted: 13 March 2020

Published: 07 April 2020

Citation:

More-Bayona JA, Torrealba D,

Thomson C, Wakaruk J and

Barreda DR (2020) Differential Effects

of Drinking Water Quality on

Phagocyte Responses of Broiler

Chickens Against Fungal and Bacterial

Challenges. Front. Immunol. 11:584.

doi: 10.3389/fimmu.2020.00584

\section{Juan A. More-Bayona ${ }^{1}$, Débora Torrealba ${ }^{1}$, Caitlin Thomson ${ }^{1}$, Jeremy Wakaruk ${ }^{2}$ and Daniel R. Barreda ${ }^{1,2 *}$ \\ 1 Laboratory of Immunology and Animal Health, Department of Biological Sciences, University of Alberta, Edmonton, AB, Canada, ${ }^{2}$ Department of Agricultural, Food and Nutritional Sciences, University of Alberta, Edmonton, AB, Canada}

Combinatorial effects of xenobiotics in water on health may occur even at levels within current acceptable guidelines for individual chemicals. Herein, we took advantage of the sensitivity of the immune system and an avian animal model to examine the impact of xenobiotic mixtures on animal health. Water was derived from an underground well in Alberta, Canada and met guidelines for consumption, but contained a number of contaminants. Changes to chicken immunity were evaluated following acute (7d) exposure to contaminated water under basal and immune challenged conditions. An increase in resident macrophages and a decrease in CD8+ lymphocytes were identified in the abdominal cavity, which served as a relevant site where immune leukocytes could be examined. Subsequent intra-abdominal immune stimulation detected differential in vivo acute inflammatory responses to fungal and bacterial challenges. Leukocyte recruitment into the challenge site and activation of phagocyte antimicrobial responses were affected. These functional responses paralleled molecular changes in the expression for pro-inflammatory and regulatory genes. In all, this study primarily highlights dysregulation of phagocyte responses following acute (7d) exposure of poultry to contaminated water. Given that production food animals hold a unique position at the interface of animal, environmental and human health, this emphasizes the need to consider the impact of xenobiotic mixtures in our assessments of water quality.

Keywords: drinking water quality, phagocyte function, acute inflammation, fungal and bacterial challenges, comparative immunology

\section{INTRODUCTION}

Water is the most important element for any living organism $(1,2)$, essential to immune function and the maintenance of homeostasis. This translates into meaningful implications for animal health and performance. To date, most studies on water contamination have focused on the effects of individual contaminants, and concentration values that exceed recommended levels. Given the abundance of different contaminants in the environment, we and others believe that added emphasis should be placed on the combinatorial biological effects of chemicals in these mixtures and their by-products (3-6). This, however, requires a focus on functional read-outs rather than conventional examination for the presence of a growing list of individual contaminants using 
chemical analyses. Further, it requires added availability of reagents to capture the impact of these mixtures on a range of terrestrial and aquatic organisms.

Production food animals hold a unique position at the interface of animal, environmental and human health (7-9). Among others, they serve as important sentinels for pathogens and xenobiotics. In the present study, we identified multiple contaminants present in underground water and assessed their combinatorial effects on chicken immunity following acute 7-day exposure. We focused on phagocyte responses, first measuring pre-challenge numbers for resident macrophages and their activation state, as indicators of changes to basal immunity. We then paired these with evaluation of molecular and cellular responses following in vivo intra-abdominal challenges with two well-defined fungal and bacterial models. Our fungal model, zymosan, has been widely used in comparative systems and has provided important insights into mechanisms governing the induction and control of acute inflammation (10-15). Our bacterial model, Salmonella enterica serovar Typhimurium (ST), is among the most common and relevant enteric pathogens for the food production industry and public health (16-18). ST is well established to engage phagocyte subsets, inducing marked heterophil and macrophage recruitment and activation in infected chickens $(17,19)$. Evaluation of these early changes in phagocyte numbers and function showed that contaminants in underground raw water, even within acceptable concentrations, induce marked effects on bird immunity.

\section{MATERIALS AND METHODS}

\section{Chickens}

Three-week-old Ross 708 broiler chickens (Gallus gallus) were used. All animals were housed in the Poultry Research Facility of the Agriculture, Food and Nutritional Sciences at the University of Alberta. Animals were grouped into two experimental treatments: raw underground well water (raw well water) and tap water control group (tap water). Animals were maintained according to guidelines specified by the Canadian Council on Animal Care, and protocols approved by the University of Alberta Animal Care and Use Committee. Maximum efforts were made to minimize animal stress and chickens terminated by cervical dislocation and exsanguination.

\section{Treatment}

Drinking water was administrated for 7 days. Following water treatment, chickens were abdominally challenged using zymosan (2.5 mg, Sigma Aldrich), resuspended in $500 \mu \mathrm{l}$ of $1 \mathrm{x} \mathrm{PBS}^{-/-}$ (no calcium, no magnesium). Zymosan is a well-established pathogen mimic obtained from Saccharomyces cerevisae, which promotes immune cell activation and function through mannose and $\beta$-glucans receptors. Previous in vitro and in vivo studies have shown that zymosan phagocytosis results in activation of pro-inflammatory responses that include induction of proinflammatory cytokines, production of reactive oxygen and nitrogen intermediates and increased infiltration of leukocytes, predominantly neutrophils (20-26). The zymosan dose was selected because it allowed for natural transition to resolution of acute inflammatory processes, thus providing a self-resolving peritonitis model for in vivo examination of the impact of water quality on bird immunity $(10,27-30)$. For bacterial challenges, we focused on a Salmonella enterica serovar typhimurium X4232 strain (ST). This is a nalidixic-acid resistant strain that have been broadly used to examine inflammation in multiple animal models. In our experimental design, ST was cultured on xylose lysine deoxycolate agar (XLD) for 24 hours at $37^{\circ} \mathrm{C}$ followed by culture in $\mathrm{LB}$ broth at $37^{\circ} \mathrm{C}$ at $150 \mathrm{rpm}$ for $20 \mathrm{~h}$ to obtain $10^{9}$ $\mathrm{CFU} / \mathrm{ml}$ of culture broth. ST was heat-killed at $80^{\circ} \mathrm{C}$ in a water bath for $1 \mathrm{~h}$ an $\mathrm{d}$ resuspended in $1 \mathrm{x} \mathrm{PBS}^{-/-}$. The goal was to provide a bacterially induced self-resolving immune challenge that would not suffer from confounding factors associated with microbial growth. Heat-killed ST (HKST; $10^{9} \mathrm{CFU}$ ) was resuspended in $500 \mu \mathrm{l}$ and keep at $-4^{\circ} \mathrm{C}$ until injection.

\section{Abdominal Lavage}

Chickens were euthanized via cervical dislocation and animals were bled to minimize potential blood contamination into the abdominal cavity, as previously described $(13,14)$. Leukocytes were recovered by injecting $20 \mathrm{ml}$ of incomplete RPMI media into the lower left quadrant at the abdominal site. Harvested leukocytes were kept at $4^{\circ} \mathrm{C}$. Non-injected chickens were used as negative controls.

\section{Definition of Phagocyte Populations}

Phagocytes were identified using imaging flow cytometry along with modified Wright-Giemsa staining (Hema3). For Hema3 (Fischer Scientific), leukocyte cytospins were stained according to the manufacturer's specifications and analyzed through light microscopy. For imaging flow cytometry, a dot plot of events using area (size, $\mathrm{x}$-axis) vs intensity channel 6 (internal complexity, y-axis) was created to define the different subpopulations using leukocyte morphology and nuclear staining (Draq5). Monoclonal antibodies further helped to define specific leukocyte subpopulations. Monocyte/macrophage labeling was performed using the KUL01 antibody marker (Abcam). This antibody recognizes a homolog of the mammalian mannose receptor C-type, MRC1 (also called CD206) (31, 32). The KUL01 antibody was added to a final concentration of $1: 1000$, followed by $30 \mathrm{~min}$ incubation at $41^{\circ} \mathrm{C}$. Cells were washed in $\mathrm{PBS}^{-/-}$and fixed in $1 \%$ of formaldehyde. $\mathrm{PE}$ anti-chicken $\mathrm{CD}^{+}$and $\mathrm{Cy} 5$ anti-chicken $\mathrm{CD}^{+}$(Abcam) were used for $\mathrm{CD} 4^{+}$and $\mathrm{CD} 8^{+}$ $\mathrm{T}$ lymphocytes staining, respectively. Anti $\mathrm{CD} 4^{+}$antibody was added at 1:1000 dilution and anti CD ${ }^{+} \mathrm{T}$ lymphocytes antibody at 1:2000 dilution. Leukocytes were incubated at $-4^{\circ} \mathrm{C}$ for $30 \mathrm{~min}$ and followed by $20 \mathrm{~min}$ at room temperature. Hoechst 33342 was added as nuclear staining.

\section{Analysis of Phagocyte Function}

ROS production was measured using CellROX (Molecular probes), as previously described $(13,14)$. NO production was determined using DAF-FM diacetate (Molecular Probes) oxidation staining. DAF-FM diacetate reagent was diluted 1:25 in $1 \mathrm{x} \mathrm{PBS}^{-/-}$and $4 \mu \mathrm{l}$ was added for incubation for $30 \mathrm{~min}$ at $41^{\circ} \mathrm{C}$. Phagocytes were washed with $1 \times \mathrm{PBS}^{-/-}$and fixed in $1 \%$ formaldehyde. 
TABLE 1 | Primers used for qPCR analysis.

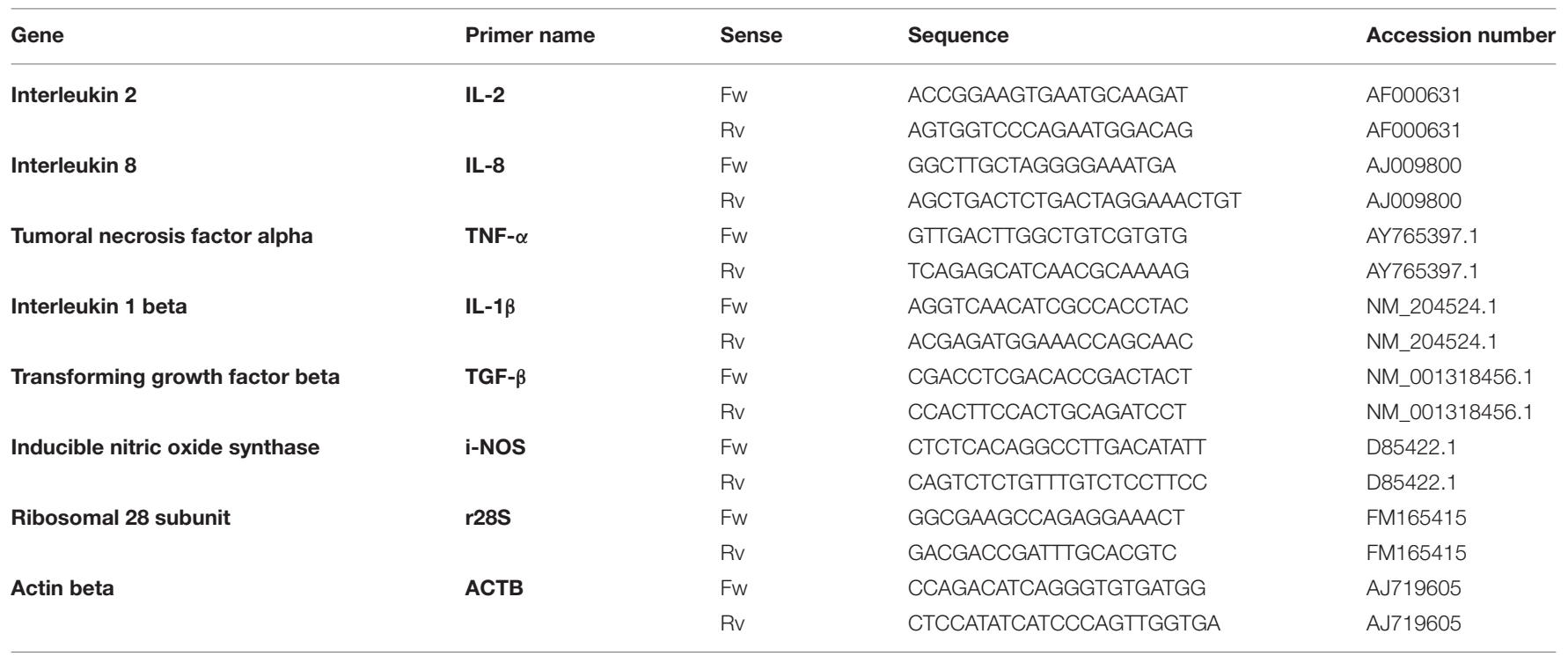

\section{Gene Expression}

Abdominal leukocytes were kept in Trizol (Thermo Fisher Scientific), stored in liquid nitrogen and total RNA was extracted following manufacturer's specifications. RNA concentration and quality were evaluated using Nanodrop ND-1000 (Thermo Fisher Scientific) and Bioanalyser-2100 with the RNA 6000 Nano Kit (Agilent Technologies), respectively. Samples had a RIN higher than 7.5. cDNA was synthesized with $650 \mathrm{ng}$ of total RNA in a final volume of $20 \mu \mathrm{l}$ using iScript Kit (BioRad). Transcripts of r28s and ACTB were used as reference genes for quantification purposes. qPCR was carried out using SYBR Green (prepared by Molecular Biology Services Unit staff at the University of Alberta), $500 \mathrm{nM}$ of primers and $2.5 \mu \mathrm{l}$ of cDNA previously diluted in $10 \mu \mathrm{l}$ of final volume; and evaluated using the QuantStudio 6 Flex Real-Time PCR System (Applied Biosystems). Primers for qPCR are described in Table 1. Relative quantification was performed according to Livak's method (33). Samples were run in triplicates and results were statistically analyzed using Two-way ANOVA followed by Sidak's multiple comparison test to estimate differences between treatments.

\section{Statistical Analysis}

GraphPad Prism software was used to assess statistical differences and significance between groups using two-way ANOVA and Sidak's multiple comparison tests. Statistics with $p<0.05$ were considered significant.

\section{RESULTS}

\section{Raw Water Source Selection and Analysis}

Raw well water was obtained from a poultry producer in south eastern Alberta, Canada located in an area of high chemical and high fertilizer expense $(20,34)$, and in close proximity to point source contamination from a natural gas extraction well (located approximately $500 \mathrm{~m}$ from water source). The local producer uses this well water as the water source for one chicken coup. Unique to this producer is another nearby coup under his operation, which uses municipal tap water as its water source. We considered this an excellent opportunity to examine source effects as both cohorts were managed by the same producer using equivalent procedures, with only the water being a variable. There were also anecdotal accounts of animal health and performance effects, and the producer had noted a significant difference in the quality of litter across both locations. The litter of the coup where well water is consumed was said to contain higher levels of moisture likely due to a laxative effect. This required the facility have greater ventilation to maintain suitable humidity.

Water was analyzed according to CALA (Canadian Association for Laboratory Accreditation) and ISO17025 standards. Parameters selected for analysis are known to have detrimental effects on human and animal health (21). Higher levels of ammonia, phosphates or potassium for the area pointed to a presence of contaminants stemming from agricultural activities. A summary of the results found in the raw water source used and comparisons to tap water are provided in Table 2. From more than 150 elements tested in the well water used, some were found to be near but above acceptable guidelines, including calcium carbonate and bicarbonate, sulfates and sodium. We also found trace concentrations of total penta chloro-dibenzo-p-dioxin and octa chloro-dibenzo-p-dioxin, members of a group known as dioxins. Additional parameters were significantly lower than maximum acceptable levels and, thus, not included in the table.

\section{Raw Well Water Increases Basal Numbers of Abdominal Resident Macrophages While Decreasing CD8 ${ }^{+} \mathrm{T}$ Lymphocytes in Chickens}

We first evaluated whether acute exposure to raw well water resulted in changes to basal chicken immunity and used the abdominal cavity as a relevant site where immune leukocytes 
TABLE 2 | Summary of xenobiotics found in raw and tap water.

\begin{tabular}{|c|c|c|c|c|}
\hline Parameter name & Units & $\begin{array}{l}\text { Results } \\
\text { (raw) }\end{array}$ & $\begin{array}{l}\text { Results } \\
\text { (tap) }\end{array}$ & $\begin{array}{c}\text { Max. acceptable } \\
\text { concentration }\end{array}$ \\
\hline $\begin{array}{l}\text { Total dissolved } \\
\text { solids }\end{array}$ & ppm & 970 & 230 & 1000 \\
\hline Chloride & ppm & 23 & 6.5 & 200 \\
\hline $\mathrm{Ph}$ & $\mathrm{pH}$ & 8.40 & 8.03 & $7.0-10.5$ \\
\hline $\begin{array}{l}\text { Alkalinity (CaCO3, } \\
\text { Bicarb) }\end{array}$ & ppm & 570 & 170 & 300 \\
\hline Nitrates & ppm & $<0.01$ & 0.32 & 25 \\
\hline Sulfates & ppm & 220 & 77 & 200 \\
\hline Iron & ppm & 0.06 & $<0.06$ & 0.3 \\
\hline Calcium & ppm & 6.6 & 46 & 60 \\
\hline Copper & ppm & 0.0034 & 0.42 & 0.6 \\
\hline Magnesium & ppm & 0.93 & 13 & 125 \\
\hline Manganese & ppm & 0.015 & $<0.0040$ & 0.05 \\
\hline Sodium & ppm & 390 & 17 & 150 \\
\hline Zinc & ppm & 0.0061 & 0.034 & 1.5 \\
\hline Total Penta CCD* & $\mathrm{pg} / \mathrm{L}$ & 1.54 & N/A & $\begin{array}{c}2^{\star \star}- \\
2.3^{\star \star \star} \mathrm{pg} / \mathrm{Kg} / \text { day }\end{array}$ \\
\hline Octa CDD* & $\mathrm{pg} / \mathrm{L}$ & 5.7 & N/A & $\begin{array}{c}2^{\star \star}- \\
2.3^{* \star *} \mathrm{pg} / \mathrm{Kg} / \text { day }\end{array}$ \\
\hline Fecal coliforms & CFU & 0 & 0 & 0 \\
\hline
\end{tabular}

${ }^{*}$ chloro-dibenzo-p-dioxin.

${ }^{\star \star}$ World health organization (35).

${ }^{\star \star \star}$ European Commisision's Scientific Committee on Food (36).

could be examined. We identified a higher proportion of abdominal macrophages in animals that consumed raw well water for $7 \mathrm{~d}$ compared to animals which were provided with normal tap water, even though the former still met stringent Canadian drinking water guidelines for consumption (Figure 1, $p=0.012$ ). In contrast, we observed a reduced proportion of CD8+ T lymphocytes in the raw well water group compared to the tap water control group (Figure 1, $p=0.023$ ). No changes were observed in the proportions of CD4+ leukocytes between control and raw well water exposed groups under non-immune challenged conditions (data not shown).

\section{Drinking Water Quality Affects Leukocyte Recruitment During Acute Inflammation}

Results above showed that drinking water quality affected resident leukocyte numbers even when exposure was limited to 7 days. We then evaluated the impact under immune challenged conditions. Birds were injected intra-abdominally with zymosan or heat killed Salmonella enterica serovar Typhimurium (HKST) following this same $7 \mathrm{~d}$ water exposure. Leukocyte recruitment was assessed 4, 12 and $48 \mathrm{~h}$ after in vivo challenge (Figure 2A). Values were not significantly different across raw well water and tap water (control) treatments when total leukocyte migration numbers were considered. Higher resolution analyses, however, showed extended heterophil retention within the abdominal cavity for birds in the raw well water group following in vivo bacterial challenge (Figure 2B, $48 \mathrm{~h}$ post-challenge, $p=$ 0.019). Concurrently, the proportion of monocyte/macrophages remained lower in the raw well water group at this $48 \mathrm{~h}$ time point (Figure 2B, $p=0.004$ ). Although our fungal challenge showed similar kinetics of leukocyte recruitment, dominated by heterophil infiltration, the effect on heterophil retention was limited to the bacterial challenge (Figure 2B).

\section{Drinking Water Quality Affects Phagocyte Function at the Immune Challenge Site}

ROS and NO production were selected as highly conserved antimicrobial mechanisms of immune defense. Fungal stimulation led to a higher proportion of ROS producing leukocytes in chickens that consumed raw well water $(60 \%$ compared to $30 \%$ ROS producing leukocytes in control tap water group; Figure 3, $p=0.0009)$. In contrast, no difference was observed between tap (control) and raw well water groups following heat-killed Salmonella stimulation. Chicken NO production was also affected by drinking water quality. However, unlike ROS this was not evident when total leukocyte population was considered. Higher resolution analysis at the single cell level using imaging flow cytometry showed that levels of heterophil NO production were downregulated by $12 \mathrm{~h}$ post zymosan challenge in animals exposed to raw well water, compared to the control group which remained high at this time point (Figure 3, $p=0.041$ ). As with production of reactive oxygen intermediates, the impact on $\mathrm{NO}$ production was limited to our fungal challenge.

\section{Raw Well Water Promoted Expression of Pro-inflammatory Leukocyte Genes During Acute Inflammation}

The impact of raw well water on leukocyte recruitment and function highlighted above paralleled changes observed at the molecular level. Effects were most pronounced in the zymosanchallenged group and impacted both kinetics and absolute levels of pro-inflammatory gene expression. Differences were evident as early as $(4 \mathrm{~h})$, where leukocytes derived from birds supplied with raw well water showed significantly higher levels of gene expression for TNF $\alpha$, IL-1 $\beta$, IL-8, and iNOS (Figure 4; TNF $\alpha$ $p<0.001$; IL-1 $\beta p=0.0013$; IL-8 $p<0.0001$; iNOS $p<$ $0.0001)$. Notably, anti-inflammatory cytokine gene expression (TGF- $\beta$ ) was also upregulated early in the acute inflammatory response among leukocytes derived from the raw well water group, consistent with dysregulation of the immune response (Figure 4, $p<0.0001$ ). Parallel experiments using our heat killed Salmonella enterica serovar Typhimurium in vivo challenge also displayed a dysregulated phenotype with upregulation of IL8 and downregulation of IL-2 in the raw well water group. However, the effect was less marked than with the fungal in vivo challenge model shown above.

\section{DISCUSSION}

Assessment of water quality has become more challenging given the number and variety of xenobiotics that can enter the water supply from various sources. For pesticides and fertilizers, monitoring studies have shown that they are reaching Canada's water resources (22-25). While concentrations of these chemicals 

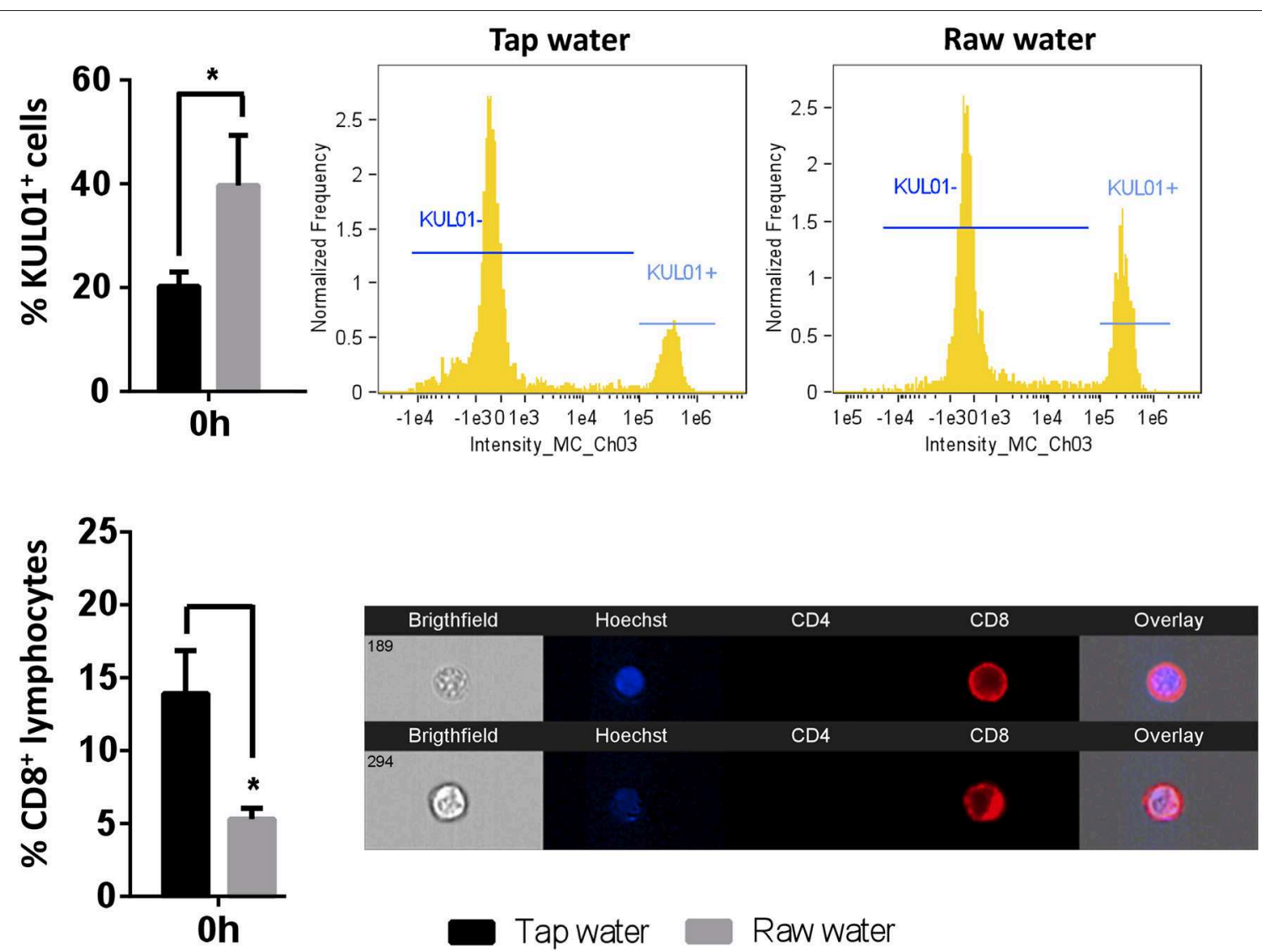

Tap water Raw water

FIGURE 1 | Short-term exposure to raw well drinking water impacts resident macrophage and lymphocyte numbers in broiler chickens. Birds were exposed to well water as drinking source for $7 \mathrm{~d}$. Leukocytes were isolated through abdominal lavage and incubated with anti-PE-KUL01 antibody, to determine the proportions of resident macrophages. CD8T lymphocytes were identified using a Cy5 anti-chicken CD8 antibody. Data represents mean \pm SEM $(n=6)$. Differences were assessed using two-way ANOVA and Sidak's multiple comparison test. ${ }^{*} p<0.05$.

in water are generally low, they are commonly detected, particularly in regions of significant urban or agricultural development. Overall, farmland applications of pesticides and fertilizers have almost tripled in Alberta over the last 25 years (23). For pesticides, Alberta shows the second-highest amount of pesticide utilization in Canada, and although the relatively dry climate reduces the potential risk for water contamination throughout the year, significant risk still exists during episodes of surface water runoff (26). Unfortunately, the River Pesticide Index from which these values are derived from does not measure the risk to aquatic life, irrigated crop production, or drinking water sources (25). At the same time that agriculture operations continue to expand in this province, both the number and size of smaller communities near agricultural centers in the North and South Saskatchewan River Basins continue to increase $(37,38)$. These smaller communities display the highest vulnerability to water contamination episodes because of the proximity to the sources of contamination, their reliance of the water resources for drinking water, recreation, and irrigation of field crops, and because personnel and infrastructure for water treatment is often limited compared to larger population centers (39-41). As such, the convergence between expanding agricultural operations and local rural populations creates added risk for occurrence of acute and chronic diseases associated with exposure to pathogens and/or chemicals. In one example, the high levels of mixed animal agriculture in the Oldman river region have already been linked to one of the highest incidences of gastroenteritis in Canada $(42,43)$. These issues are not limited to Canada, but increasingly relevant globally (44-48).

Production animals fill a central position at the interface environment, animal and human health. They serve as sentinels for multiple infections and environmental contaminants, and impacts to their health status can facilitate the spread of infectious agents to consumers and the environment. Given the broad use of water resources for production animal rearing both geographically and throughout an animal's development, drinking water can play a significant and sustained role in the health of these animals. In this study, we identified no instances of morbidity or mortality in any of the treatment groups. However, we identified multiple effects of drinking water on bird immunity, even though this well water met stringent Canadian drinking water guidelines for consumption. Short-term (7d) exposure 
A

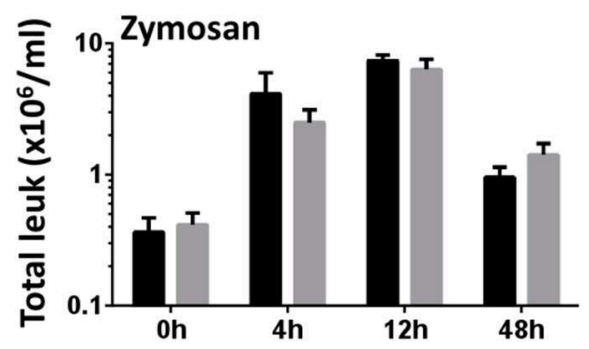

B
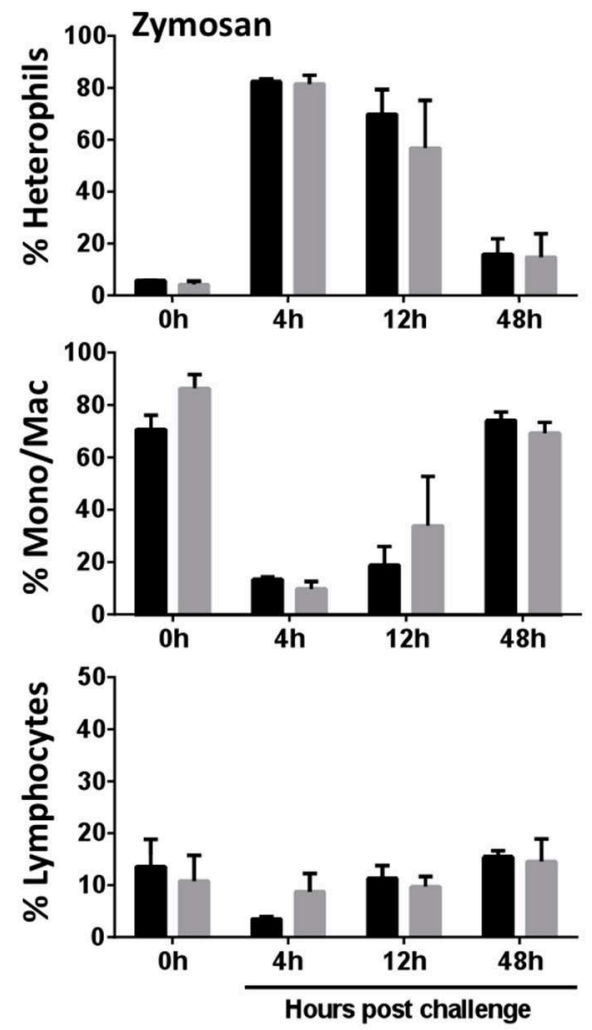

Tap water

\section{Raw water}
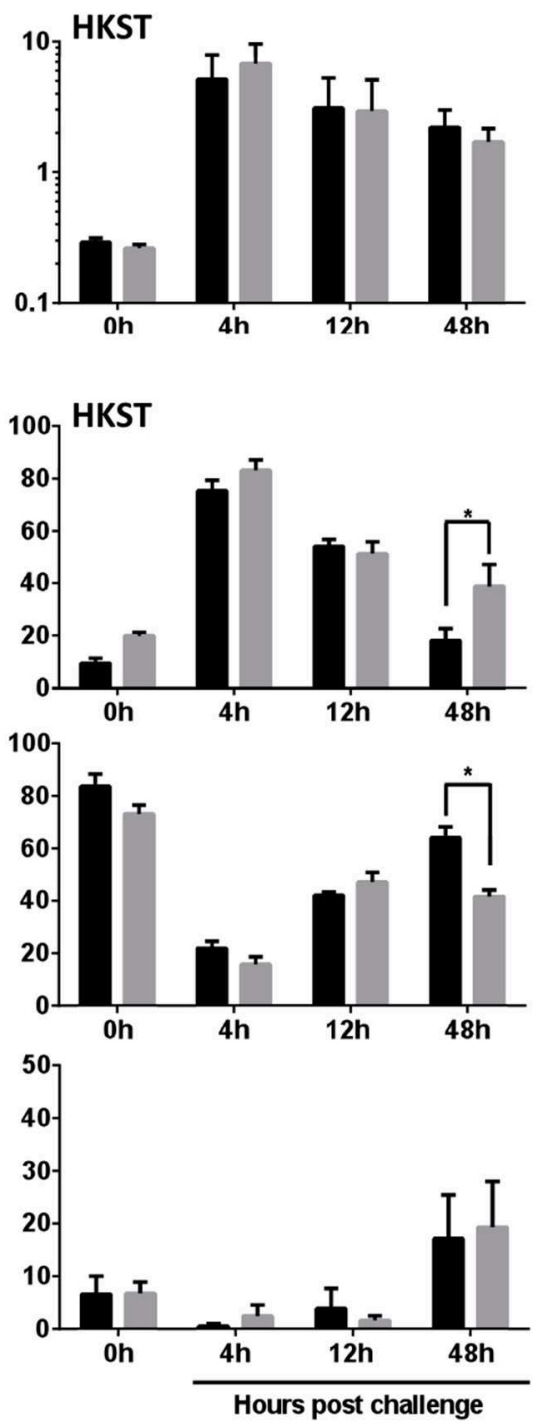

FIGURE 2 | Raw well water differentially affects leukocyte recruitment following fungal and bacterial in vivo stimulation. Following $7 \mathrm{~d}$ raw well water consumption, birds were challenged in vivo via intra-abdominal route using zymosan (fungal) or heat killed Salmonella enterica serovar Typhimurium (HKST; bacterial). Abdominal lavages were performed at 0, 4, 12, and $48 \mathrm{~h}$ post intra-abdominal challenge. (A) Total leukocytes were counted using a hemocytometer and light microscopy. (B) The proportions of heterophils, monocyte/macrophages and lymphocytes were determined using Imaging flow cytometry along with conventional Wright Giemsa staining. Data represents mean $\pm \operatorname{SEM}(n=7)$. Differences were evaluated using two-way ANOVA and Sidak's multiple comparison test. ${ }^{\star} p<0.05$.

to xenobiotic mixtures through drinking water changed the resident leukocyte profile of test birds, with greater numbers of macrophages and lower numbers of CD8+ lymphocytes in the chicken abdominal cavity. We expect that these basal changes are associated with changes in the capacity of these birds to recognize and respond to pathogen infiltration. This is consistent with previous reports using murine models, where tissue macrophage numbers were shown to change following chemical exposure $(49,50)$. Notably, this is the first report of changes in the abundance of $\mathrm{CD} 8^{+} \mathrm{T}$ lymphocytes after xenobiotic exposure. Our understanding of leukocyte subsets in chickens, and reagents to examine them, continues to expand. It will be interesting to take advantage of these in the coming years as we look to gain added resolution into the impact of xenobiotics on subset composition for the leukocyte pool under basal and immune challenged conditions.

The contributions of immune defenses to host integrity are tightly linked to the effective induction and resolution of inflammatory processes (51-53). Deviations in efficient leukocyte recruitment to infection sites can severely impact host health, disease transmission and performance $(52,53)$. Our results showed extended heterophil retention within the abdominal 

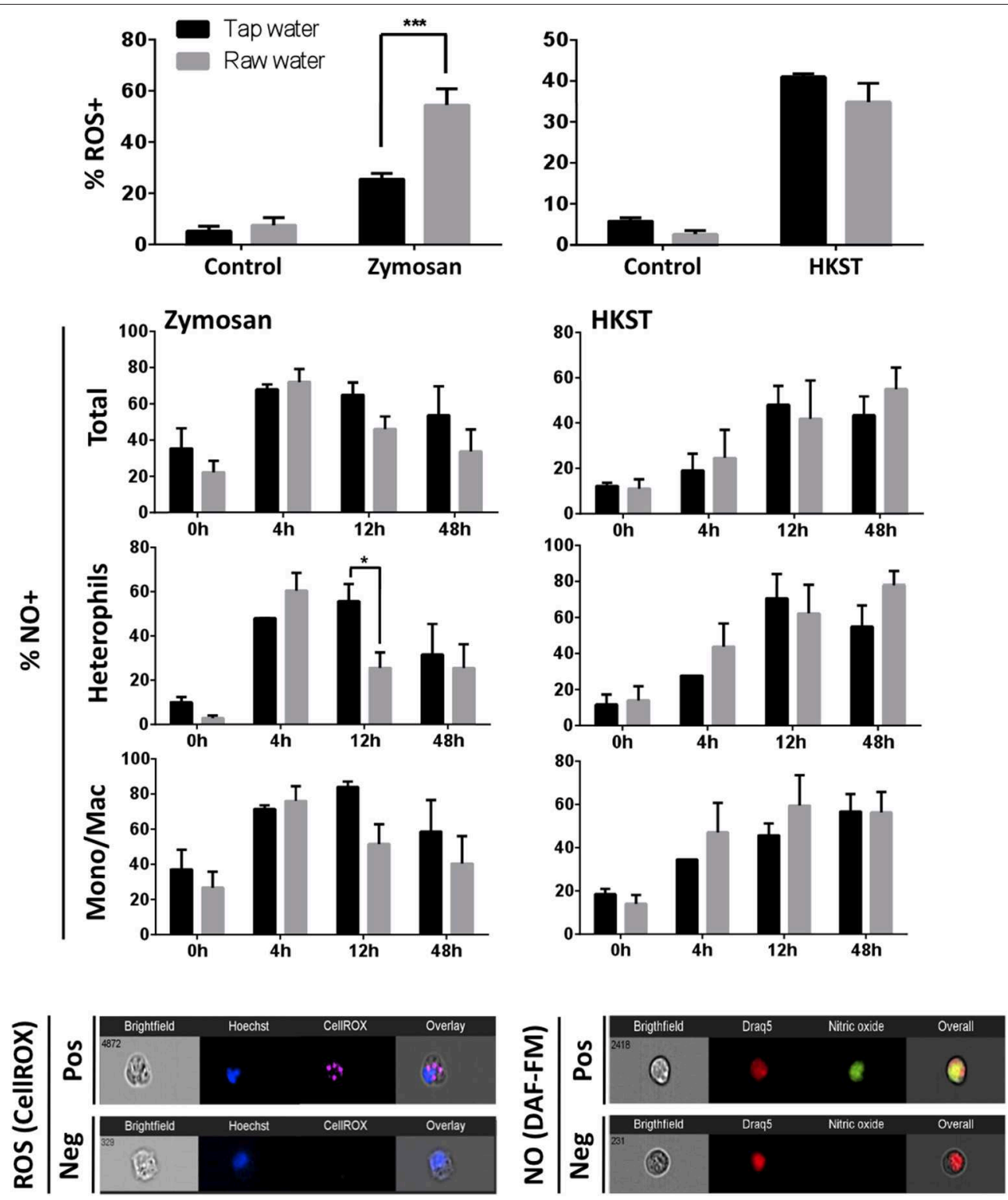

FIGURE 3 | Raw well water treatment differentially impacts phagocyte antimicrobial responses. Birds were exposed to well water as drinking source for 7d and subsequently exposed to fungal or bacterial in vivo stimulation. Respiratory burst (ROS production) capacity in isolated leukocytes was assessed using CellROX. Nitric oxide $(\mathrm{NO})$ production was determined using DAF-FM diacetate. Data represents mean \pm SEM $(n=5)$. Significant differences were identified using two-way ANOVA and Sidak's multiple comparison test $\left({ }^{\star \star \star} p<0.001 ;{ }^{\star} p<0.05\right)$. Representative images from an ImageStream MKII flow cytometer show positive (pos) and negative (neg) cells following staining with CellROX and DAF-FM diacetate.

cavity for birds in the raw well water group following in vivo bacterial challenge (Figure 5). These higher heterophil levels in late phases of acute inflammation coupled to maintenance of ROS and NO production capacity, suggests an extended pro-inflammatory phenotype following bacterial challenge. The concurrent lower proportion of monocyte/macrophages late in the acute inflammation process further suggests a lower capacity and/or slower transition toward activation of tissue repair mechanisms at the infection site. This has broad implications for resolution of inflammatory responses, energy expenditure and the efficient activation of downstream adaptive mechanisms of immunity upon bacterial infection. Interestingly, differential effects were detected in leukocyte recruitment and retention between the fungal and bacterial in vivo challenges used in this study. Characterization of phagocyte ROS and NO production also highlighted differential effects among fungal and bacterial challenges. Among the potential implications of these effects, is a differential impact of xenobiotics to the susceptibility of these animals to various infectious challenges. 


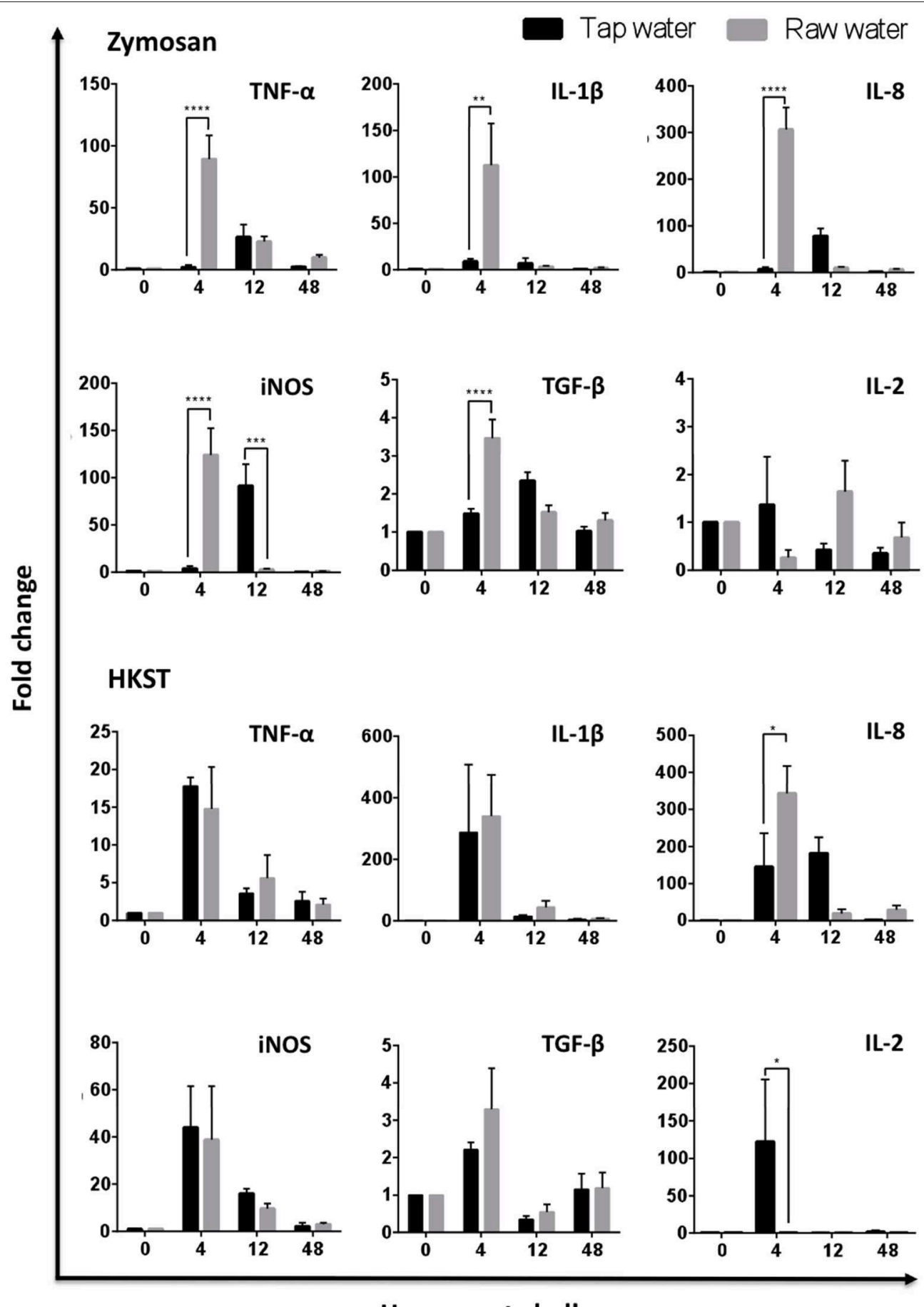

Hours post challenge

FIGURE 4 | Raw well water treatment induces changes in leukocyte expression of pro-inflammatory and regulatory genes. Birds were exposed to well water as drinking source for $7 \mathrm{~d}$ and subsequently exposed to fungal or bacterial in vivo stimulation. Abdominal leukocytes were harvested at $0,4,12$, and $48 \mathrm{~h}$ post challenge. Gene expression was analyzed by qPCR. Data represents mean \pm SEM $(n=4)$. Significant differences were analyzed using two-way ANOVA and Sidak's multiple comparison test. ${ }^{*} p<0.05,{ }^{* \star} p<0.01,{ }^{\star \star *} p<0.001,{ }^{* \star \star *} p<0.0001$.

The impact of raw well water on leukocyte recruitment and function highlighted above paralleled changes observed at the molecular level. The kinetics and absolute levels of gene expression changed for multiple pro-inflammatory mediators, particularly among zymosan challenged birds. Importantly, gene expression of the anti-inflammatory 


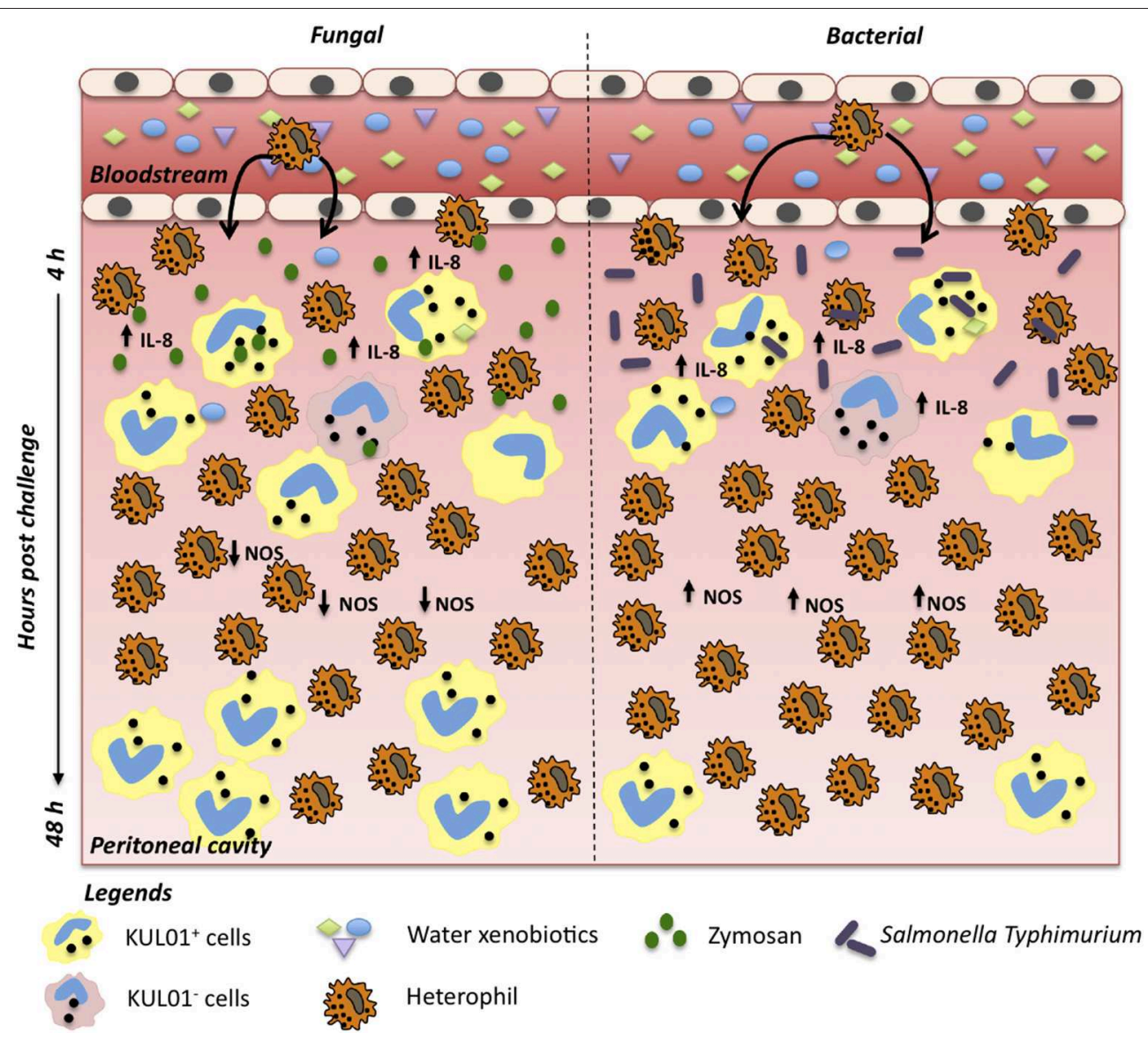

FIGURE 5 | Differential effect of raw water in chicken acute inflammation against fungi and bacterial challenges. After intra-abdominal challenge, following acute exposure to raw water, promotes differential effect on inflammatory process. In a fungi model, we observed marked heterophil infiltration a few hours after in vivo challenge, likely driven by a more prominent resident macrophage pool along with an upregulated IL-8, TNF- $\alpha$, and IL-1 $\beta$ expression. At $12 \mathrm{~h}$ post challenge, NO levels and iNOS gene expression were downregulated. Acute inflammatory process is largely complete by $48 \mathrm{~h}$ post challenge, allowing a return to homeostasis. In a bacterial model, we also observed marked heterophil infiltration which paralleled up-regulation of IL-8 gene expression. No down-regulation effect was observed in the cellular and molecular levels of $\mathrm{NO}$ at $12 \mathrm{~h}$ post-challenge. However, $48 \mathrm{~h}$ post challenge, heterophil proportions remained higher, while monocyte/macrophage pool remained lower, consistent with a longer acute pro-inflammatory response.

cytokine TGF- $\beta$ was also upregulated early in the acute inflammatory response among leukocytes derived from the raw well water group. This is consistent with molecular changes observed in other models with individual chemicals, where exposure was shown to promote higher expression in genes including IL- $1 \beta$, TGF $\beta$, and others $(50,54,55)$. Together, this suggests dysregulation of the acute inflammatory response following exposure to xenobiotics in drinking water. It will be important to determine if these alterations further compromise the engagement of adaptive mechanisms of immunity and potentially impact the development of long-term protection against pathogens.

Altogether, this work provides added depth in our understanding of the impact of drinking water quality on immune function. Among the greatest advantages of this strategy, is the temporal integration of individual and interactive effects of exposure to multiple contaminants into a few measurable parameters. Our work also demonstrates that these functional platforms can be setup in nonclassical animal models to target discrete effects on animal populations that sit at the interface between animal, public and environmental health. As others have already noted, unfortunately, current maximum acceptable levels for individual contaminants in water do not account for the synergistic biological effects of related chemicals and their breakdown products $(3,4,56,57)$. Further, comprehensive screens for individual contaminants are cost prohibitive and thus can only focus on a discrete number of representative compounds. Thus, it is critical that combinatorial effects of chemicals that act through the same or parallel pathways complement existing assessments of water quality. Where possible, performance metrics should also be used as added relevant indicators for the impact of water quality on bird health. 


\section{DATA AVAILABILITY STATEMENT}

The raw data supporting the conclusions of this article will be made available by the authors, without undue reservation, to any qualified researcher.

\section{ETHICS STATEMENT}

The animal study was reviewed and approved by the University of Alberta Animal Care and Use Committee.

\section{AUTHOR CONTRIBUTIONS}

JM-B and DB jointly conceived the experimental design. JM-B conducted experiments, analyzed, and interpreted the data. DT conducted qPCR experiments and edited parts of the manuscript. CT contributed with part of ex vivo experiments. JW edited part of the manuscript and provided logistic support. JM-B and DB wrote the manuscript. All authors approved this final version.

\section{REFERENCES}

1. Ball P. Water is an active matrix of life for cell and molecular biology. Proc Natl Acad Sci USA. (2017) 114:13327-35. doi: 10.1073/pnas.1703781114

2. Wiggins PM. Role of Water in Some Biological Processes. Microbiol Rev. (1990) 54:432-49. doi: 10.1128/MMBR.54.4.432-449.1990

3. Alexander J, Hetland R, Vikse R, Dybing E, Eriksen G, Farstad W, et al. Combined toxic effects of multiple chemical exposures. Nor Sci Comm Food Saf. (2008) 1-105.

4. Escher BI, Fenner K. Recent advances in environmental risk assessment of transformation products. Environ Sci Technol. (2011) 45:3835-47. doi: 10.1021/es1030799

5. Robert J, McGuire CC, Kim F, Nagel SC, Price SJ, Lawrence BP, et al. Water contaminants associated with unconventional oil and gas extraction cause immunotoxicity to amphibian tadpoles. Toxicol Sci. (2018) 166:39-50. doi: 10.1093/toxsci/kfy179

6. Robert J, McGuire CC, Nagel S, Lawrence BP, Andino FJ. Developmental exposure to chemicals associated with unconventional oil and gas extraction alters immune homeostasis and viral immunity of the amphibian Xenopus. Sci Total Environ. (2019) 671:644-54. doi: 10.1016/j.scitotenv.2019. 03.395

7. Goossens KE, Ward AC, Lowenthal JW, Bean AGD. Chicken interferons, their receptors and interferon-stimulated genes. Dev Comp Immunol. (2013) 41:370-6. doi: 10.1016/j.dci.2013.05.020

8. Magor KE, Miranzo Navarro D, Barber MRW, Petkau K, Fleming-Canepa X, Blyth GAD, et al. Defense genes missing from the flight division. Dev Comp Immunol. (2013) 41:377-88. doi: 10.1016/j.dci.2013.04.010

9. Stewart CR, Keyburn AL, Deffrasnes C, Tompkins SM. Potential directions for chicken immunology research. Dev Comp Immunol. (2013) 41:463-8. doi: 10.1016/j.dci.2013.05.011

10. Cash JL, White GE, Greaves DR. Zymosan-induced peritonitis as a simple experimental system for the study of inflammation. Methods Enzymol. (2009) 461:379-96. doi: 10.1016/S0076-6879(09)05417-2

11. Kolaczkowska E, Barteczko M, Plytycz B, Arnold B. Role of lymphocytes in the course of murine zymosan-induced peritonitis. Inflamm Res. (2008) 57:272-8. doi: 10.1007/s00011-007-7131-1

12. Leypoldt JK, Kamerath CD, Gilson JF. Acute peritonitis in a C57BL/6 mouse model of peritoneal dialysis. Adv Perit Dial. (2007) 23:66-70.

13. More-Bayona JA, Karuppannan AK, Trites MJ, Barreda DR. Application of imaging flow cytometry for characterization of acute inflammation in non-classical animal model systems. Methods. (2017) 112:167-74. doi: 10.1016/j.ymeth.2016.06.013

\section{FUNDING}

This work was supported by Natural Sciences and Engineering Council of Canada (NSERC grant number RGPIN-201805768) and Alberta Livestock and Meat Agency (ALMA grant number 2015R036R) grants to DB. JM-B was supported by a National Fund for Innovation in Science and Technology (FINCyT/Innovate-Peru) scholarship and a Graduate Teaching Assistantship by the Department of Biological Sciences at the University of Alberta. DT was supported by a CONICYT-Chile postdoctoral fellowship (Becas Chile N: 74170029).

\section{ACKNOWLEDGMENTS}

We would also like to offer special thanks to the Poultry Research Facility staff of the Department of Agricultural, Food and Nutritional Science at the University of Alberta for their contributions during this study.

14. More-Bayona JA, Kumar A, Barreda DR. Contribution of leukocytes to the induction and resolution of the acute in flammatory response in chickens. Dev Comp Immunol. (2017) 74:167-77. doi: 10.1016/j.dci.2017.04.018

15. Rao TS, Currie JL, Shaffer AF, Isakson PC. In vivo characterization of zymosan-induced mouse peritoneal inflammation. J Pharmacol Exp Ther. (1994) 269:917-25.

16. Ipinza F, Collao B, Monsalva D, Bustamante VH, Luraschi R, Alegría-Arcos $\mathrm{M}$, et al. Participation of the salmonella OmpD porin in the infection of RAW264.7 macrophages and BALB/c mice. PLoS ONE. (2014) 9:e111062. doi: 10.1371/journal.pone.0111062

17. Kaiser P, Rothwell L, Galyov EE, Barrow PA, Burnside J, Wigley P. Differential cytokine expression in avian cells in response to invasion by Salmonella typhimurium, Salmonella enteritidis and Salmonella gallinarum. Microbiology. (2000) 146:3217-26. doi: 10.1099/00221287-146-12-3217

18. Riber U, Lind P. Interaction between Salmonella typhimurium and phagocytic cells in pigs Phagocytosis, oxidative burst and killing in polymorphonuclear leukocytes and monocytes. Vet Immunol Immunopathol. (1999) 67:259-70. doi: 10.1016/S0165-2427(98)00233-5

19. Kogut MH, McGruder E, Hargis B, Corrier D, Deloach J. Characterization of the Pattern of Inflammatory Cell Influ in Chicks Following the Intraperitoneal Administration of Live Salmonella enteritidis and Salmonella enteritidisimmune Lymphokines. Poult Sci. (1995) 74:8-17. doi: 10.3382/ps.0740008

20. Agricultural and Agri-Food Canada. Fertilizer Expense Index for the Agricultural Area of Alberta. (2001). Agricultural and Agri-Food Canada.

21. MacDonald D, Caux P, Fan G, Walker S, Bonnell M. Canadian water quality guidelines for the protection of agricultural water uses - protocols. Can Counc Minist Environ. (1999) 1-21.

22. Alberta Environment and Sustainable Resource Development. Pesticide Index. (2011). Alberta Environment and Sustainable Resource Development.

23. Alberta Environment and Sustainable Resource Development. Impact of Land Use on Water. (2013).

24. Anderson A-M, Saffran KA, Byrtus G. Pesticides in Alberta Surface Waters. Water Sciences Branch and Pesticide Management Branch, Alberta Environmental Protection. (1997).

25. Phelan C. Pesticides in Alberta’s Agricultural Watersheds: A Synthesis. Alberta Agriculture and Rural Development. (2012).

26. Eilers W, MacKay R, Graham L, Lefebvre A. Environmental Sustainability of Canadian Agriculture: Report \#3. In Agri-Environmental Indicator Report Series. Agriculture and Agri-Food Canada. (2010).

27. Brown GD, Taylor PR, Reid DM, Willment JA, Williams DL, MartinezPomares L, et al. Dectin-1 is a major beta-glucan receptor on macrophages. J Exp Med. (2002) 196:407-12. doi: 10.1084/jem.20020470 
28. Chadzinska M, Leon-Kloosterziel KM, Plytycz B, Lidy Verburg-van Kemenade BM. In vivo kinetics of cytokine expression during peritonitis in carp: evidence for innate and alternative macrophage polarization. Dev Comp Immunol. (2008) 32:509-18. doi: 10.1016/j.dci.2007.08.008

29. Cuzzocrea S, Zingarelli B, Sautebin L, Rizzo A, Crisafulli C, Campo GM, et al. Multiple organ failure following zymosan-induced peritonitis is mediated by nitric oxide. Shock. (1997) 8:268-75. doi: 10.1097/00024382-199710000-00006

30. Rieger AM, Konowalchuk JD, Grayfer L, Katzenback BA, Havixbeck JJ, Kiemele MD, et al. Fish and mammalian phagocytes differentially regulate pro-inflammatory and homeostatic responses in vivo. PLoS ONE. (2012) 7:e47070. doi: 10.1371/journal.pone.0047070

31. Mast J. Characterisation of chicken monocytes, macrophages and interdigitating cells by the monoclonal antibody KUL01. Vet Immunol Immunopathol. (1998) 61:343-57. doi: 10.1016/S0165-2427(97)00152-9

32. Staines K, Hunt LG, Young JR, Butter C. Evolution of an expanded mannose receptor gene family. PLoS ONE. (2014) 9:e110330. doi: 10.1371/journal.pone.0110330

33. Livak KJ, Schmittgen TD. Analysis of relative gene expression data using realtime quantitative PCR and the $2 \wedge$ delta delta CT method. Methods. (2001) 25:402-8. doi: 10.1006/meth.2001.1262

34. Agricultural and Agri-Food Canada. Chemical Expense Index for the Agricultural Area of Alberta. (2001). Agricultural and Agri-Food Canada.

35. WHO. Polychlorinated dibenzodioxins, polychlorinated dibenzofurans, and coplanar polychlorinated biphenyls. In: Safety Evaluation of Certain Food Additives and Contaminants. WHO Food Additives Series, No. 48. Geneva: World Health Organization (2002). Available online at: http://www.inchem. org/documents/jecfa/jecmono/v48je20.htm

36. EC. Fact Sheet on Dioxin in Feed and Food: Opinion of the Scientific Committee on Food on the Risk Assessment of Dioxins and Dioxin-Like PCBS in Food. Brussel: European Commisision's Scientific Committee on Food (2001). Available online at:https://ec.europa.eu/food/sites/food/files/safety/docs/cs_ contaminants_catalogue_dioxins_report-20001117.pdf

37. Alberta Municipal Affairs. Municipal Census \& Population Lists. (2012).

38. Alberta Treasury Board and Finance. Economy \& Statistics. (2013). Available online at: http://www.finance.alberta.ca/aboutalberta/index.html (accessed November 01, 2019).

39. Hrudey SE, Hebert PC, Stanbrook MB, Sibbald B, Flegel K, MacDonald N, et al. Safe water? Depends on where you live! Can Med Assoc J. (2008) 178:975:7. doi: 10.1503/cmaj.080374

40. Koning CW, Saffran KA, Little JL, et al. Water quality monitoring: the basis for watershed management in the Oldman River Basin, Canada. Water Sci Technol. (2006) 53:153-61. doi: 10.2166/wst.2006.308

41. Peterson H, Torchia M. Safe drinking water for rural Canadians. Can Med Assoc J. (2008) 179:55. doi: 10.1503/cmaj.1080061

42. Jokinen CC, Edge TA, Koning W, Laing CR, Lapen DR, Miller J, Mutschall S, et al. Spatial and temporal drivers of zoonotic pathogen contamination of an agricultural watershed. J Environ Qual. (2012) 41:242-52. doi: 10.2134/jeq2011.0203

43. Khakhria R, Woodward D, Johnson W. Salmonella, Shigellae, pathogenic E. coli, Campylobacter and Aeromonas identified in Canada: Annual Summary (1994). National Laboratory for Enteric Pathogens, LCDC, Health Canada. (1996).

44. Carr RM, Blumenthal UJ, Mara DD. Guidelines for the safe use of wastewater in agriculture: revisiting WHO guidelines. Water Sci Technol. (2004) 50:31-8. doi: $10.2166 /$ wst. 2004.0081
45. Frisbie SH, Mitchell EJ, Sarkar B. Urgent need to reevaluate the latest World Health Organization guidelines for toxic inorganic substances in drinking water. Environ Health. (2015) 14:63. doi: 10.1186/s12940-015-0050-7

46. Sobsey MD, Bartram S. Water quality and health in the new millennium: the role of the World Health Organization Guidelines for Drinking-Water Quality. Forum Nutr. (2003) 56:396-405.

47. Moe CL, Rheingans RD. Global challenges in water, sanitation and health. $J$ Water Health. (2006) 4(Suppl. 1):41-57. doi: 10.2166/wh.2006.0043

48. Sousa JCG, Ribeiro AR, Barbosa MO, Pereira MFR, Silva AMT. A review on environmental monitoring of water organic pollutants identified by EU guidelines. J Hazard Mater. (2018) 344:146-62. doi: 10.1016/j.jhazmat.2017.09.058

49. Vogel A, Nishimura N, Sciullo E, Wong P, Li W, Matsumura F. Modulation of the chemokines KC and MCP-1 by 2, 3, 7, 8-tetrachlorodibenzop -dioxin (TCDD) in mice. Arch Biochem Biophys. (2007) 461:169-75. doi: 10.1016/j.abb.2007.01.015

50. Vogel C, Donat S, Do O. Effect of subchronic 2,3,7,8-tetrachlorodibenzop-dioxin exposure on immune system and target gene responses in mice: calculation of benchmark doses for CYP1A1 and CYP1A2 related enzyme activities. Arch Toxicol. (1997) 71:372-82. doi: 10.1007/s002040050401

51. Freire M, Van Dyke T. Natural resolution of inflammation. Periodontology (2000). (2013). 63:149-64. doi: 10.1111/prd.12034

52. Gilroy D, De Maeyer R. New insights into the resolution of inflammation. Semin Immunol. (2015) 27:161-8. doi: 10.1016/j.smim.2015. 05.003

53. Sansbury BE, Spite M. Resolution of acute inflammation and the role of resolvins in immunity, thrombosis, and vascular biology. Circ Res. (2016) 119:113-31. doi: 10.1161/CIRCRESAHA.116.307308

54. Lamb CL, Cholico GN, Perkins DE, Fewkes MT, Oxford JT, Lujan TJ, et al. Aryl Hydrocarbon receptor activation by TCDD modulates expression of extracellular matrix remodeling genes during experimental liver fibrosis. Biomed Res Int. (2016). 2016:5309328. doi: 10.1155/2016/53 09328

55. Moos AB, Baecher-Steppan L, Kerkvlietbt NI. Acute inflammatory response to SRBC in mice treated with TCDD. Toxicol Appl Pharmacol. (1994) 127:331-5. doi: 10.1006/taap.1994.1169

56. Klecka G, Persoon C, Currie R. Chemicals of emerging concern in the Great Lakes Basin: an analysis of environmental exposures. Rev Environ Contam Toxicol. (2010) 207:1-93. doi: 10.1007/978-1-4419-6406-9_1

57. Vanderslice RR, Orme J, Ohanian EV, Sonich-Mullin C. Problems in assessing the risks of mixtures of contaminants in drinking water. Toxicol Ind Health. (1989) 5:747-55. doi: 10.1177/074823378900 500512

Conflict of Interest: The authors declare that the research was conducted in the absence of any commercial or financial relationships that could be construed as a potential conflict of interest.

Copyright (C) 2020 More-Bayona, Torrealba, Thomson, Wakaruk and Barreda. This is an open-access article distributed under the terms of the Creative Commons Attribution License (CC BY). The use, distribution or reproduction in other forums is permitted, provided the original author(s) and the copyright owner(s) are credited and that the original publication in this journal is cited, in accordance with accepted academic practice. No use, distribution or reproduction is permitted which does not comply with these terms. 